Seminars, Conferences, Addresses

\title{
Annual Meeting of The American Sociological Association
}

\author{
8-12 Rabī al Awwal 1415 / August 5-9, 1994 \\ Los Angeles, California
}

This conference, which consisted of many sessions, was very well attended. Since giving a review of each session is impractical, I will discuss those points that relate to academic strategies and intellectual trends and that are relevant to Muslim academia.

Organization: Social disciplines have become very diverse. Sociology, if not at the top, is ne exception. Thus it seems that organizing a conference around a theme is rather limiting. This meeting, entitled "The Challenge of Democratic Participation," consisted of nine categories: plenary, thematic, regular/section session, special session, didactic seminar, open topic refereed roundtables/informal discussion roundtables, book panel/poster sessions, and professional and teaching workshops. Plenary sessions discussed subjects of national or statewide policy concerns, such as "Reconstructing the Political," or "Reflection of the 1992 Los Angeles Rebellion: Views of Community Leaders." The thematic sessions analyzed democratic participation on many levels: labor's role in democratization, trade unions, religion and institutions, governance in higher education, mass media strategies, and gender. The thirty-three special sessions focused on timely topics: pan-ethnicity in the United States; the relevance of the Black church; the politics of educational texts, health care, and the family values debate: xenophobia in Europe; fundamentalism in the Middle East; NAFTA; and federal support to social sciences. 
Regular sessions discussed mainstream sociological subjects and were elaborations on sociological principles in the study of such different social dilemmas as social movements and collective identity, educational equality, religion and national identity, gender in a global perspective, rural life structures, political culture and resources, minorities and assimilation, and many others. Section sessions were basically of the same nature as regular sessions. However, they are the equivalent of a sociological "school" that has organized itself into a section within the larger ASA. Didactic seminars were meant to discuss recent scholarly trends and developments. In reality, they were "methodology" sessions.

Roundtable sessions were designed to fill in the space and complete discussion on specific topics that the general program could not accommodate. Book panel sessions concentrated on groundbreaking books, and poster sessions allowed participants to meet face-to-face with authors.

Intellectual Trends and Interests: How intellectually stimulating was this conference? Of course, the answer depends partially on the criteria used for evaluation. Abstract discussions were rather few, and sociological theory was kept to a minimum. There was little talk of metatheory or of the theoretical crossroads at which different sociologies depart. Nine sessions dealt with pure theory, four with comparative history, and nine with methods. Most sessions were substance oriented. Political sociology, which included global as well as local concerns on different forms of societal conflict, came at the top and was followed by sex and gender. Gender was the paradigm of many other sessions in the sociology of religion, race and ethnicity, knowledge and technology, and social psychology. Race and inequality was the third most analyzed subject. These three areas (political sociology, sex and gender, and race and ethnicity) constituted more than one-third of all sessions (see end of report).

To answer the question posed at the beginning, many sessions were innovative as regards the use of sociological principles to study and analyze the world. At the same time, a more fundamental discussion of questions in social knowledge, its scope, and its limitation was avoided. Surprisingly, the challenges of European sociology were not mentioned - even the term "postmodernism" was heard only rarely. It seems that American sociology is well contented with itself and its achievements.

Despite sociology's diversity, academic divisions were routinized and advocates of each orientation were satisfied with their own territory. On the other hand, boundaries between sociological schools might have become more blurred. In a single paper, one could find elements from conflict tradition to social psychology. Does such a trend indicate a subjectivity-laden element in social sciences (picking up elements from schools that seem to support one's predetermined conclusions) or is sociology asserting its maturity in an interdisciplinary/interschool orientation? Such an issue becomes more pressing when we consider that academic research does not talk vry much about its epistemological foundations. These are left to one's guess and to the obscurity of a chaotic system of knowledge. 
Public Relations: To a certain extent, sociology has a history of bad public relations. After all, what is the expected image of a science that mainly exposes social pathologies or, when it talks in a constructive manner, seeks to transform a comfortable status quo and legitimate change toward an uncertain future that is a source of fear for the general public? This issue has been a headache for sociology as a discipline, as it needs both approval and funding for its very survival. It seems that sociology has learned its lesson: when the media covers its public conference, care must be taken as to what is said. After all, issues of public funding and of impressing the "out-group" audience must be recognized and handled properly and successfully.

At one point in the recent history of sociology, there were intellectually intriguing and inspiring debates. Homan's presidential address was an assault on traditional sociology and a call to "bring men back in"-a new vision for a "good" sociology as he sees it. The presidential address for ASA 1994 was titled "Hiroshima, the Holocaust, and the Politics of Exclusion," a timely subject that reflects how relevant sociology is for public issues. I am not a fan of Homan's ideas. What I mean to convey is merely the intellectual challenge presented to the attendees and that this challenge was a priority. Seemingly, the priority now is achieving a better image.

Three dissertations were nominated for the "Dissertation Award." The one chosen was a research paper on AIDS patients. Academic activism was also present on the level of applied research. There were several studies on gay and lesbian issues, gender issues, and on Muslims. Some of the latter were innovative, and others that were merely reproductions of western perspectives on different social milieux. However, there was no paper on Muslims in the United States, a marked contrast to the many papers presented on the Asian community and by Asians whom we stereotypically like to think of as technical, not social, specialties.

It might be fair to depict annual conferences as academic "shows," vehicles for networking, and places were the politics of presenting challenging, but poised, ideas dictate issues and content. Unfortunately, academic conferences, as they stand today, are not forums for the rigorous exchange or refining of ideas.

Main subjects discussed (categorized by specialty):

Political Sociology and Social Movements (41 sessions): Conflict, war, conflict resolution, inventing peace intervention, genocide, xenophobia, mobilization, labor and democratization, political repression and democratization, democracy in the Middle East, electoral behavior, world inequality, policy and planning, social movements, military sociology, world system.

Sex and Gender (31 sessions): Income, stratification, work relation, political participation, family and policy issues, women in former communist countries, sociology of population and women, international fertility, gays and lesbians.

Race, Ethnicity and Inequality (23 sessions): Inequality, gender and race inequality, educational attainment, mobility, immigration, new communities, Asians, Latino women.

Economic Sociology (20 sessions): Inner cities, informal economy, international poverty, corporation, homelessness, development, urban/rural issues.

Medical Sociology and the Sociology of Aging (16 sessions): Aging, drug abuse, AIDS, health policies and reform, medical ethics. 
Sociology of the Family and Sociology of Children (16 sessions): Work, violence in the family, custody, parent child relations, sexuality and the family, value of children.

Educational Sociology (13 sessions): School reform, stratification and higher education, undergraduate education.

Deviance (12 sessions): Crime, drugs, violence.

Culture (12 sessions): Mass media, sports and leisure, art.

Organization and Occupation (12 sessions).

Sociology of Law (7 sessions).

Environment and Technology (7 sessions): New technology and the environment, feminist perspective on the environment.

Knowledge and Technology ( 6 sessions): Sociology of science, feminism, computers.

Sociolegy of Religion (6 sessions): Identity and minority religions, intemal structure, women participation in religion, national identity and religion, American Jewry, decline of religious participation.

Social Psychology (4 sessions): Race, women.

Ethnomethodology (4 sessions).

Sociology of Emotions (3 sessions).

Historical Sociology ( 3 sessions).

Theory: General ( 9 sessions): New sociological debates, sociology of knowledge, culture, structure.

Theory: Comparative History (4 sessions): Methods of historical comparison.

Methods ( 9 sessions): Qualitative methods, microcomputing, quantitative methods.

Mazen Hashem

Islamic Center of Southem California

Los Angeles, California 